\title{
Ball Throwing Machine Design To Develop Footballers' Technical Attributes
}

\author{
Cemile Arslan $^{1 *}$ (D) Mustafa Arslan ${ }^{2}$ (D) , Gökhan Yalçın ${ }^{3}$ (D) Turgut Kaplan $^{4}$ (D), \\ Humar Kahramanlı Örnek ${ }^{5}$ [] \\ 'Konya Technical University, Vocational School of Technical Sciences, Department of Electronics and Automation, Konya, Turkey \\ ${ }^{2}$ Konya Technical University, Vocational School of Technical Sciences, Department of Electricity and Energy, Konya, Turkey \\ ${ }^{3}$ Konya Technical University, Vocational School of Technical Sciences, Department of Machinery and Metal Technologies, Konya, Turkey \\ ${ }^{4}$ Selcuk University, Faculty of Sport Sciences, Department of Trainer Education, Konya, Turkey \\ ${ }^{5}$ Selcuk University, Faculty of Technology Department of Computer Engineering, Konya, Turkey
}

\begin{abstract}
For a football player to perform well in football, it is necessary to improve his technical and tactical skills. Improving these skills is enabled with the repetition of the same positions that the football player has the ball. The repetitions of these same positions can be performed with the aid of a machine. In this study, a football throwing machine design that can provide direction and velocity for the ball in a repeatable and controllable manner is generated for full educational evaluation. Ball loading canister on the ball throwing machine enabled to use of many balls. There are a couple of ball throwing wheels both are made of polyurethane material and have a concave surface. These wheels are mounted on a body for axial rotation on common ground. Each wheel's rotation speed can be adjusted individually. To determine the horizontal-vertical direction of movement of the ball, two linear actuators are used. Ball's velocity, direction, orbit, and throwing laps are controlled electronically. All controls concerning ball throwing are carried out via Delta PLC (Programmable Logic Controller) and HMI (Human Machine Interface) panel. A user interface is developed for controls made via PLC. Owing to the interface, different training plans are designed by handler or trainer via operator panel, and footballer is provided to train in various densities. To prevent toppling tripod system, and to carry easily a towing arm is used. The machine can work with an accumulator or feed directly from the grid circuit.
\end{abstract}

Keywords: Ball throwing machine, player training, individual training, PLC

\section{INTRODUCTION}

In our country, football love and participation are at an indisputable extent. Nevertheless, the desired success level has not yet been reached. It can be said that the most important factor to determine a football match's quality is footballers having high-level technical capacity. A fine technique is a footballer's performing appropriate movements in the most efficient way (Taşkın, 2005).

Football is a sport played with feet. Football requires some technical competence like passing, crossing, and free-kick, shoot, dribbling, blocking and cutting the balls, ball controls, and headers to be performed efficiently. A successful player is expected to handle the ball with his feet, throw curveballs, pass his friends, and kick the ball with his feet inside, outside, tip and heel kick. Being capable of these pleases both footballer and the audience.
To have a fine technique a footballer is required to control his dominance over the ball in any case of kicking or passing. This controlling can be performed with head, chest, and feet or anywhere the ball hits according to various positions. The position to stop the ball can be determined by the ball's velocity, height, direction, and footballer's technique and habits. A player's dominance over the ball and controlling it can be developed by repeats [2 - 5]. Studies show that repeating the movements results in the player memorizing them in his subconscious. This led to successful results in the match either technically or visually $[5,6]$. There is some test to determine the technique in football $[7,8]$. In some of these tests, a training footballer needs another person to pass him and since it is human passing the ball's velocity, height and direction will not be the same all the time $[4,5]$. Hence to train the same move again and again a machine will be more reliable. A machine after programmed can perform the same move several times provided that the environmental
* Corresponding author

Email: carslan@ktun.edu.tr
European Mechanical Science (2021), 5(1): 39-43

doi: https://doi.org/10.26701/ems.777400

Received: July 3, 2020

Accepted: September 8, 2020 
conditions are not changed $[2,9]$. Accordingly, a ball throwing machine can provide a player to train without another person in his training.

In our literature review, we encountered some significant studies about ball throwing machine design. Terzioğlu and et al.[10] controlled servomotor by using SCADA in their study. They used Delta branded PLC, servomotor speed control device, and HMI panel in this control. By determining the working parameters of the servomotor from the HMI screen, it is ensured to work in the desired way. Ashtekar and et al.[11] have developed a SCADA system by simulating a real-time industrial process (water level controller). They have generated the process control layer of the system by using Delta branded PLC. To control the water level they used MODBUS protocol for transmission between PLC and PC. Gupta and et al.[12] have designed a smart electricity control system. By using Delta branded PLC and HMI interface they enabled the user to monitor and control all electrical components' statuses located inside rooms or offices. Marhas and et al.[6] have developed a football throwing concept based on aerodynamic and mechanical principles to enhance goalkeeper's and striker's average attributes. They designed and developed this concept to repeat different moves, speeds, and orbits consecutively and properly. In their study, Singh and et al.[13] have constructed a bowling ball throwing machine for both entertaining and professional purposes. They aimed the machine to be portable, have a portable power source in order it to be used in the field and they also aimed it to be safe to hold still. Perumalsamy and et al.[14] have designed an automated volleyball throwing machine in their study. Movement and velocity of the ball, proper and repeatable path following of the ball programmed with Solid Works and AutoCAD software. Mahapatra and et al.[15] have developed a simulation of the computer-supported design of cricket ball throwing machine. They have designed a virtual model ball throwing machine in CATIA software of CAD/CAE software package to simulate different mechanical subunits of the machine via using ADAMS software. Saal et al.[16] developed the "Footbonaut" measurement system, in which movement speed can be diagnosed and trained, and used as a measurement and information system. It was stated that with this system, the existing talent identification and talent development structure of football players can be strengthened. In another study, Saal et al.[17] evaluated the reliability and validity of a soccer short passing test using the Footbonaut measurement system. As a result, they concluded that skilled players are significantly faster in performing short passes than less-skilled players.

In this study, a football throwing machine is designed for footballers to develop their personal attributes and performances, to train repeatedly, and to have a complete training assessment. The designed machine enables us to apply various training programs along with throwing the ball in different directions. That is to say, a footballer can train himself in various tempos after a trainer determines various plans. In the second part of the study parts of the machine are introduced and their tasks in the system are mentioned. The third part has consisted of results and suggestions.

\section{DESIGN METHODOLOGY}

Ball throwing machine designed in this study consists of three parts:

- Mechanical parts;

- Electrical-Electronical equipment;

- Software and control group.

\subsection{Mechanical Parts of the Ball Throwing Machine}

The general view of the ball throwing machine can be seen in Figure 1, the schematic view, on the other hand, can be seen in Figure 2. The machine has 2x1, 7x1 m dimensions. The body of the machine consists of an iron sheet and beam. Iron sheet plates are $1.5 \mathrm{~mm}$ thick, main beams consist of 30x50x3 mm dimensions rectangular beam and 34x3 mm dimensions pipe beam. Considering that this developed machine will be used outside mostly, to have resistance against corrosion entire body is painted with synthetic metal paint. Tripod wheeling system to prevent tipping over and towing arm for easy transportation are used. Boxes made of iron sheets are designed to protect electrical-electronic equipment from impacts and unfavorable weather conditions.

Ball throwing wheels are made of polyurethane which is resistant to snapping, tearing, and corrosion. Wheels are designed concave to grip the ball perfectly. The diameters of the wheels are $260 \mathrm{~mm}$ and their thickness is $140 \mathrm{~mm}$. These wheels are mounted horizontally with a space between them in order the ball to go through. To prevent errors due to ex-

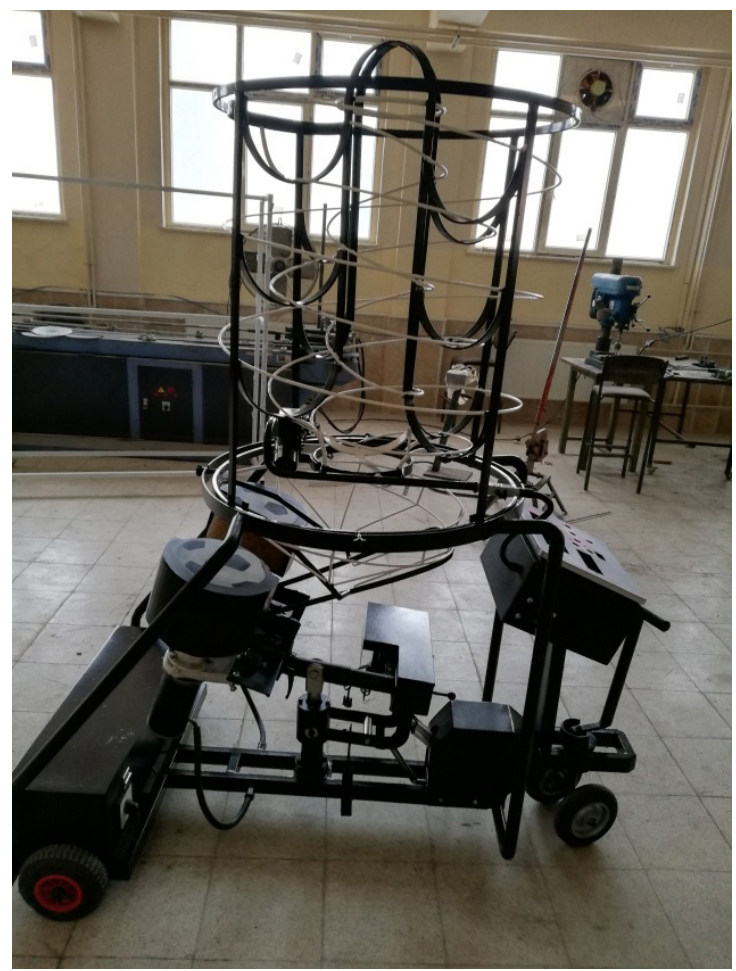

Figure 1. General View of the Ball Throwing Machine 
ternal factors, a covering part is designed for the outer part of the wheels.

Considering that the machine will de for individual use, a ball loading canister is developed. This canister has 20 balls capacity. It is constructed with steel flat with $10 \mathrm{~mm}$ thickness and its outer ring has $785 \mathrm{~mm}$ in diameter. The channel through which the ball will line up is designed with a $6 \mathrm{~mm}$ diameter pipe beam, three-level helical steps and it has a total of $820 \mathrm{~mm}$ height.

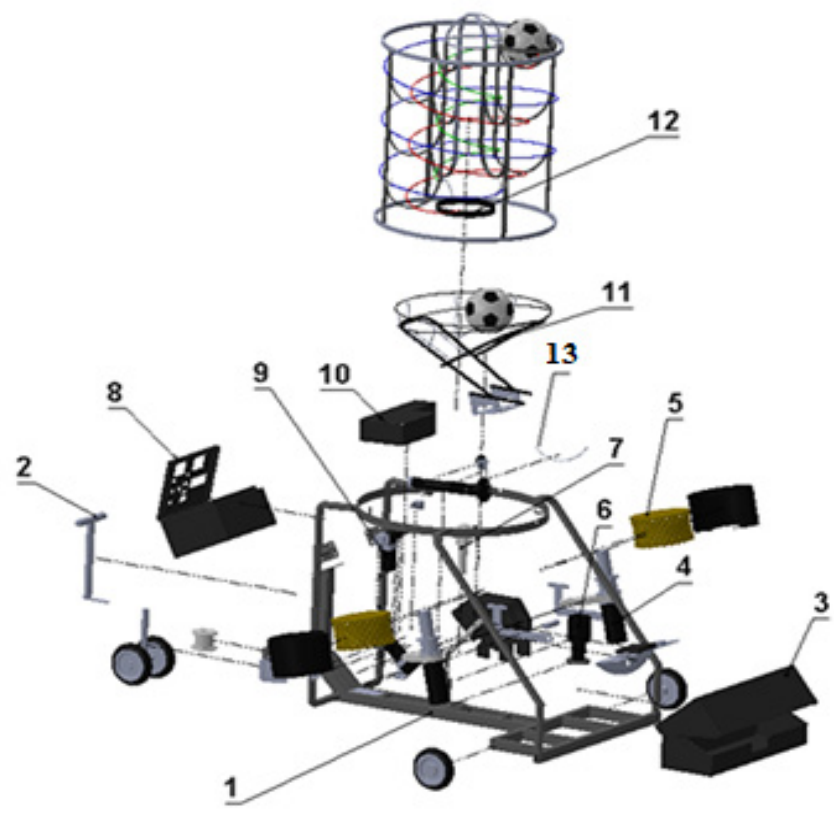

1. Chassis

2. Towing arm

3. Battery Cover

4. Motor of ball thrower wheels

5. Ball thrower wheel

6. Motor of horizontal-vertical movement piston

7. Horizontal-vertical movement piston

8. System control board

9. Ball throwing sorting motor

10. Piston cover

11. Ball sorting canister

12. Ball loading canister

13. Open-Close lever

Figure 2. Schematic View of Ball Throwing Machine

Between the ball loading canister and ball thrower wheels, there is a ball sorting canister. An open-close lever is added to the ball sorting canister to send the balls towards ball thrower wheels. One end of this lever is connected to the engine and the other end is connected to the sorting canister. The part which is connected to the loading canister is designed as a roller bearing so that it can rotate easily. Thus and so a ball can be sent to be thrown after the ball thrower wheels adjust their positions.

\subsection{Electric-Electronical Equipment of Ball Throwing Machine}

In this machine two permanent magnet DC motors, a DC gear motor, two step motors with encoders, and two linear actuators are used.

Permanent magnet DC motors provide the desired velocity to throw the ball (Figure 3) and they work independently of each other. Wheels are mounted as their direction of rotation is opposite so that they can throw the ball. By providing various DC voltages to the motor feeds, their rpm (revs per minute) can be changed and this enables the ball to follow curved or linear orbit as shown in Figure 4.

Training can be diversified by locating the machine in different locations inside the pitch.

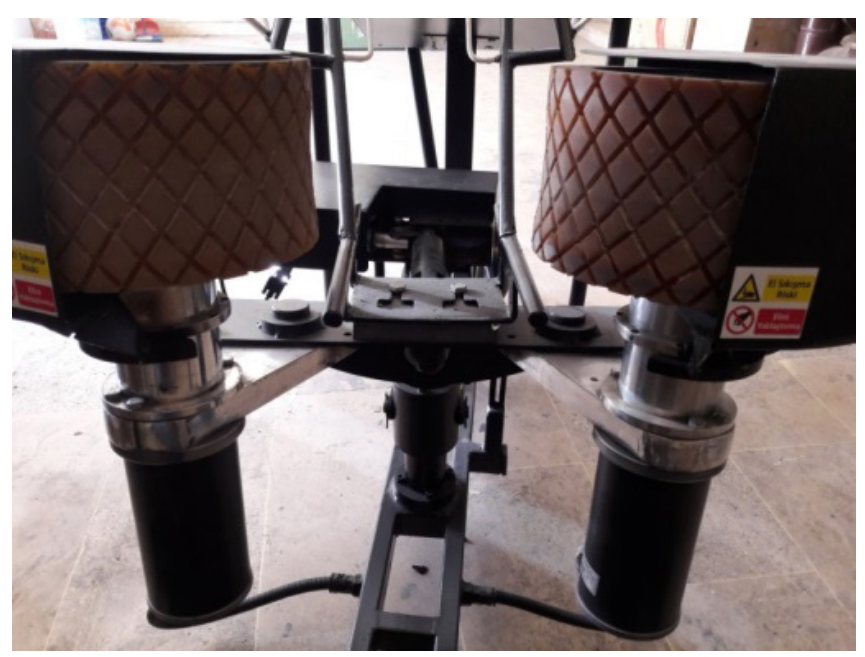

Figure 3. Ball thrower wheels and their motors

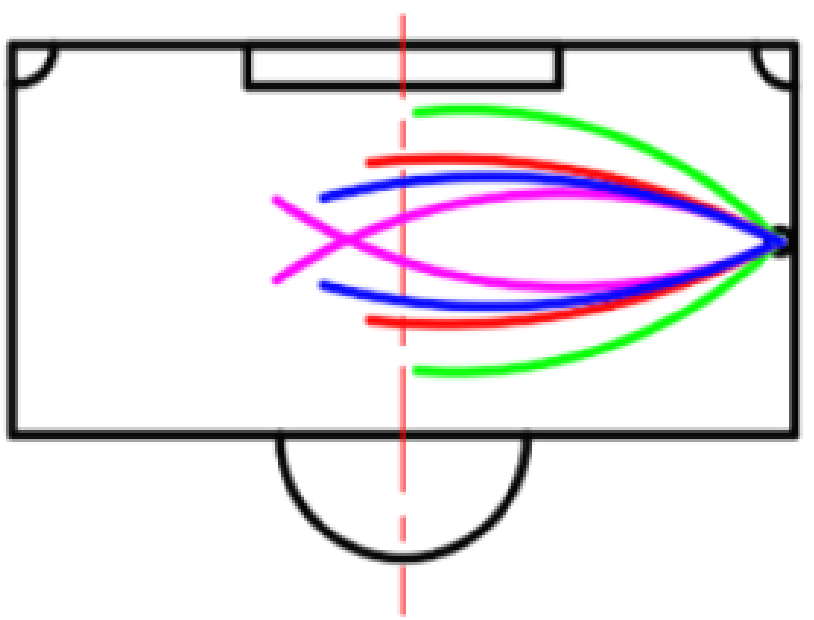

Figure 4. The orbit of the curved ball

A DC gear motor that can produce high torque at low speed is used to let the ball from the sorting canister. This DC gear motor controls the open-close lever (Figure 5).

Two step motors with encoders and Linear Actuator enabled the ball thrower wheels to move both horizontally and vertically (Figure 6). One of the motors provides horizontal, the other one provides vertical movements. The linear actuators which are used to enable horizontal-vertical movement can be moved as far as desired via the motors connected to them. This hardware can rotate ball throwing mechanism 45-degree angle maximum to left and right horizontally. This provides us total 90-degree angle ball throwing capability in the circular sector horizontally. With this hardware 45-degree maximum area can be scanned in the vertical axis, towards positive (Figure 7). 


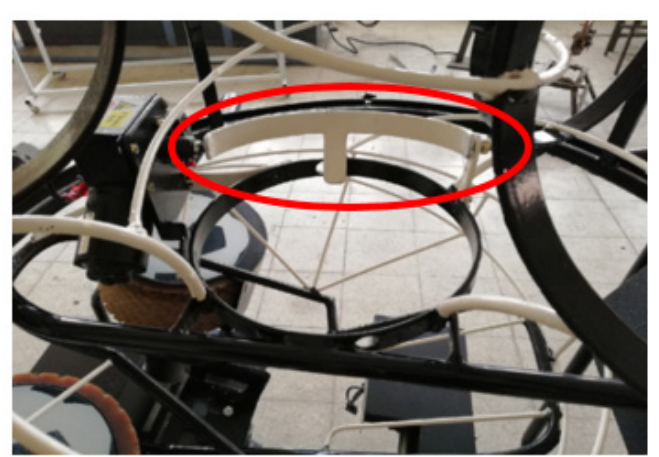

a)

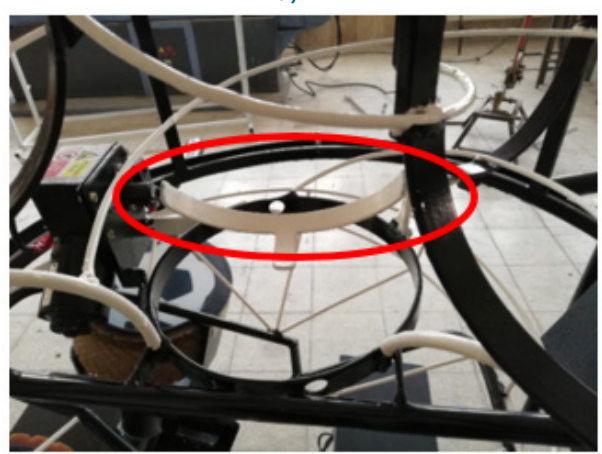

(b)

Figure 5. Open-Close lever (a) Open (b) Closed

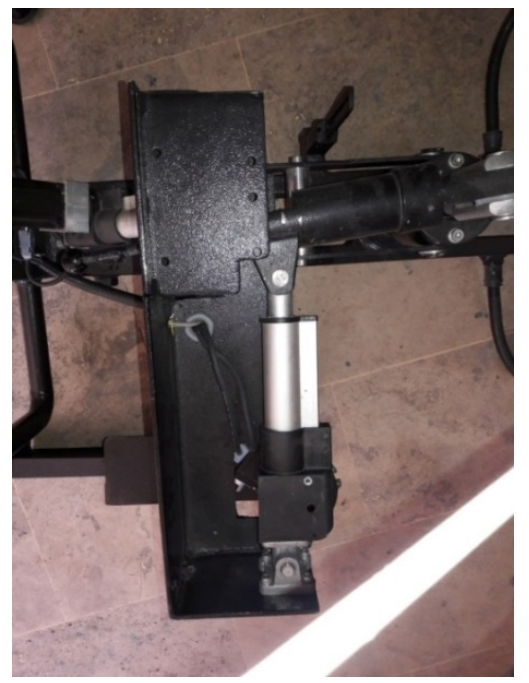

a)

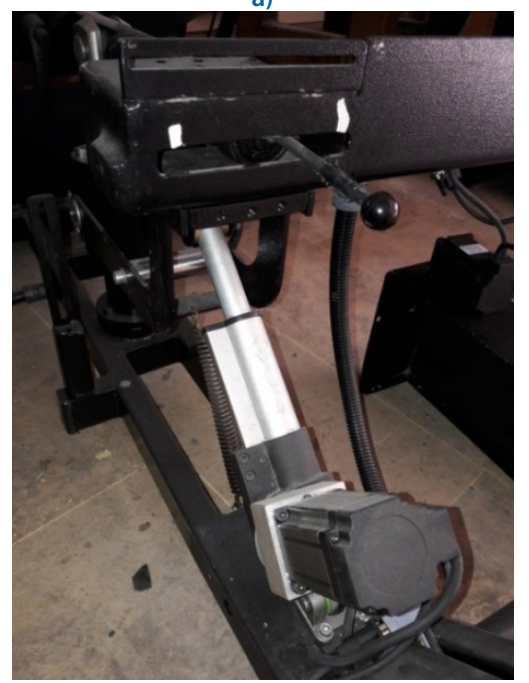

(b)

Figure 6. Horizontal-Vertical movement pistons and motors (a) Horizontal movement (b) Vertical movement

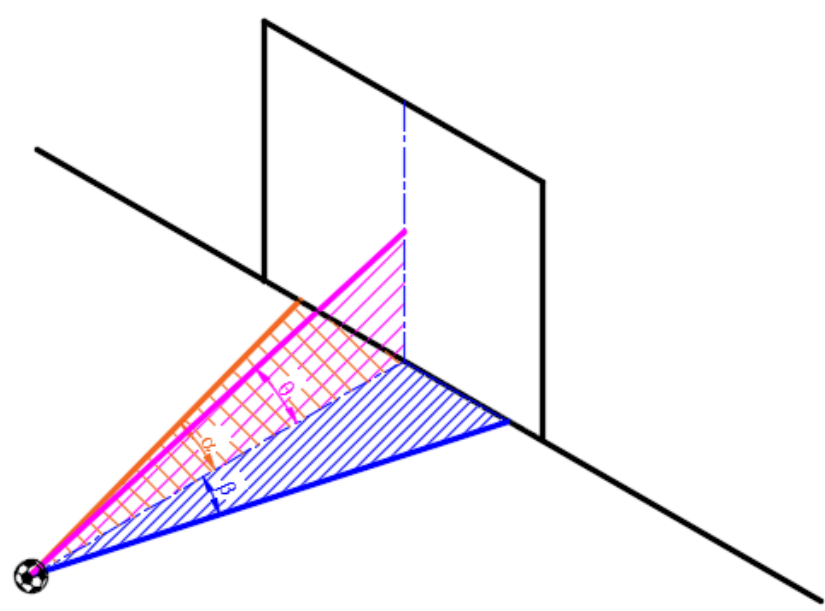

Figure 7. The schematic view of the angle is scanned horizontally and vertically.

A motor drive circuit is used to control permanent magnet DC motors. This drive circuit is selected to be compatible with a digital screen to monitor velocity. At digital screen capacity of the motor is seen between 0-100 percent according to amplitude modulation conversion. Motor's rpm is measured with a tachometer depending upon working capacity. Measurement results are seen in Table 1.

Table 1. DC Motor tachometer measurement results

\begin{tabular}{|c|c|}
\hline $\begin{array}{c}\text { DC Motor Working Capacity } \\
{[\%]}\end{array}$ & $\begin{array}{c}\text { DC Motor Rotational Speed } \\
{[\mathrm{rpm}]}\end{array}$ \\
\hline 10 & 175 \\
\hline 20 & 455 \\
\hline 30 & 745 \\
\hline 40 & 1020 \\
\hline 50 & 1280 \\
\hline 60 & 1543 \\
\hline 70 & 2015 \\
\hline 80 & 2120 \\
\hline 90 & 2365 \\
\hline 100 & 2814 \\
\hline
\end{tabular}

\subsection{Software and Control Group of the Throwing Machine}

A Delta-Cpu-DVP-14SS2 PLC and DVP-08SN addition module and a Delta DOP-A series operator panel with TFT LCD screen is used to control the ball throwing machine. For the software, the control algorithm is generated with Ladder programming language via interface found in Delta SS2 PLC device. PLC is programmed with Delta WPLSoft software and Operator Panel is programmed with DOPSoft software so that a user can activate and control the system. The communication between PLC and devices is provided with MODBUS serial communication protocol. MODBUS which uses serial communication standards is used with the RS232 serial communication interface.

With the help of the control board (Figure 8) coordinates to send the ball to, throwing frequency, repeating number can be determined and a training program can be saved and used. 


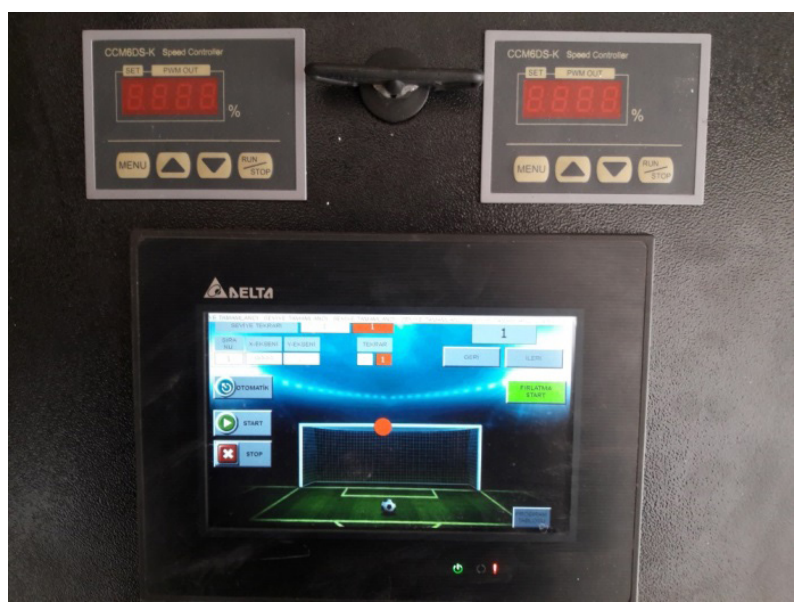

Figure 8. System Control Board

\section{RESULTS AND SUGGESTIONS}

In this study, a football throwing machine design to provide convenience for footballers in their training is carried out. This machine is developed to throw the ball in the desired time period, velocity, and position parameters. The ball loading canister which is mounted on the machine enables to load of 20 balls at a time and this way a footballer can train individually. Parameters are provided with PLC software. Due to the interface created with the software machine became controllable via the operator panel. Trainers can program the ball throwing machine to cover all parameters by controlling the machine automatically or manually with the operator panel. Studies showed that the ball throwing machine has a user-friendly interface.

This study can be seen as an example of similar motors in industrial production for suitable positioning purposes. Moreover, DC and servo motors which are controlled with PLC can also be controlled with a microcontroller if desired. Performances and cost can be compared between both systems.

\section{THANKS}

This study is supported with project number 17401043 by the University of Selcuk, Scientific Researches Projects Coordinatorship. We thank Hüseyin KORKMAZ and Ilkin KORKMAZ for their contributions during the design and construction process of the ball throwing machine.

\section{RERERENCES}

[1] Taşkın, H. (2005). Profesyonel Futbolcularda Teknik Parametrelerin Tespiti Ve Liglere Göre Değerlendirilmesi, Doktora Tezi, T.C. Selçuk Üniversitesi Sağlık Bilimleri Enstitüsü Beden Eğitimi ve Spor Anabilim Dalı, Konya.

[2] Haaland, E., \& Hoff, J. (2003). Non-dominant leg training improves the bilateral motor performance of soccer players. Scandinavian journal of medicine \& science in sports, 13(3), 179-184. DOl: 10.1034/j.1600-0838.2003.00296.x.

[3] Davids, K., Lees, A., Burwitz, L. (2000). Understanding and Measuring Coordination and Control in Kicking Skills in Soccer: Implications for Talent Identification and Skill Acquisition. Journal of Sports Sciences, 18: 703-714, DOI: 10.1080/02640410050120087.
[4] Rösch, D., Hodgson, R., Peterson, Baumann, L. T. G., Junge, A., Chomiak, J., Dvorak, J. (2000). Assessment and Evaluation of Football Performance. The American Journal of Sports Medicine, 28(5): 2939, DOI: 10.1177/28.suppl_5.s-29.

[5] Varhade, A. R., Tiwari, H., Patangrao, P. D. (2013). Cricket Bowling Machine, International Journal of Engineering Research \& Technology (IJERT), 2(12): 1920-1924.

[6] Marhas, L. S., Kanojia, K. P., Dhapodkar, V., Trivedi, M. G. (2015). Design and Development of Sport Utility: A Football Launching Machine. IJSRD - International Journal for Scientific Research \& Development| 2(12): 302-304.

[7] Özkara, A. (2002). Futbolda Testler, 1. Baskı, Illksan Matbaacılık, Ankara.

[8] Reilly, T., Holmes, M. (1983). A Preliminary Analysis of Selected Soccer Skills. Physical Education Review, 6: 64-71.

[9] Brechbuhl, C., Millet, G., Schmitt, L. (2016). Accuracy and Reliability of a New Tennis Ball Machine. Journal of Sports Science and Medicine, 15: 263-267.

[10] Terzioğlu, H., Yalçın, G. \& Kısa, M. (2019). Servomotorun SCADA ile Kontrolü. European Journal of Science and Technology, (Special Issue), 428-435, DOl: 10.31590/ejosat.638394.

[11] Ashtekar, A. S., Parvat, B. J., Kadu, C. B. (2013). Application of MODBUS to Communicate the PLC and Lab VIEW for Real Time Process Control. International Journal of Emerging Science and Engineering (IJESE), 1(11): 41-45.

[12] Gupta, M. K., Gupta P. K., Rajat Kumar Giri, R. K. \& Gupta, A. (2018). Smart Electric Control System using PLC \& HMI, International Journal of Mechanical Engineering and Technology 9(4): 548-555.

[13] Singh, A. P., Jain, A. K., Mahajan, P. (2016). Design And Fabrication of A Ball Projecting Machine. International Journal of Advance Research And Innovation, 4(3): 587-590.

[14] Perumalsamy, S., Ragupathi, P., Rahul, K. R. (2014). Design and Development of Volley Ball Practice Machine. International Journal of Latest Trends in Engineering and Technology (IJLTET), 4(1):144-156

[15] Mahapatra, A., Chatterjee, A., Roy, S. S. (2009). Modeling and Simulation of A Ball Throwing Machine, 14th National Conference on Machines and Mechanisms (NaCoMM09). NIT, Durgapur, India, December 17-18.

[16] Saal, C., Zinner, J., Büsch, D., Werner, C., Ückert, S. (2013). Der Footbonaut als Mess- und Informationssystem zu Erfassung der Agilität im Sportspiel Fußball, Zeitschrift für Gesundheit und Sport, Heft1, 53-61

[17] Saal, C., Zinner, J., Fiedler, H., Lanwehr, R., Krug, J. (2018). Reliability and validity of a soccer passing test using the Footbonaut, German Journal of Exercise and Sport Research 3: 334-340 